\title{
Perinatal management of critical aortic valve stenosis diagnosed by fetal echocardiography
}

\author{
MURRAY A ROBERTSON, PAUL J BYRNE, PATRICIA A PENKOSKE \\ From the Divisions of Pediatric Cardiology, Newborn Medicine, and Pediatric Cardiothoracic Surgery, Walter \\ C Mackenzie Health Sciences Centre, Edmonton, Alberta, Canada
}

SUMMARY A case of critical aortic valve stenosis was diagnosed in utero by echocardiography and managed successfully by early elective caesarean section and aortic valvotomy.

Critical aortic valve stenosis is infrequently diagnosed in utero, and is associated with a high neonatal mortality rate. ${ }^{12}$ Fetal echocardiography is a reliable technique for the diagnosis of abnormalities of fetal cardiac morphology and function. ${ }^{34}$ To date, however, this technique has not appreciably influenced the mortality associated with congenital cardiac lesions. Neonates with critical aortic valve stenosis commonly develop severe congestive heart failure with poor cardiac output and associated metabolic acidosis within the first few hours of life. Despite vigorous emergency medical treatment, these infants often remain critically ill and this increases the perioperative morbidity and mortality of subsequent aortic valvotomy.

We report a case of critical aortic valve stenosis diagnosed in utero at 32 weeks' gestation that was managed by early elective caesarean section at 36 weeks' gestation. Surgical aortic valvotomy performed shortly after delivery was successful.

\section{Case report}

A 29 year old woman (gravida 2, para 1) was referred to the paediatric echocardiographic laboratory for a fetal cardiac assessment at 32 weeks' gestation. A previous fetal ultrasound for suspected polyhydramnios at 30 weeks had shown a dilated, poorly contractile left ventricle. Echocardiographic studies

Requests for reprints to Dr Murray A Robertson, Division of Pediatric Cardiology, 2C300, Walter C Mackenzie Health Science Centre, Edmonton, Alberta, Canada T6G 2B7. showed increased left ventricular dimensions with an end diastolic diameter of $20 \mathrm{~mm}$ and a shortening fraction of $15 \%$. Normal left ventricular diameter and shortening fraction for this gestational age are approximately $14 \mathrm{~mm}$ and $37 \%$ respectively. ${ }^{5}$ The aortic valve appeared thickened and dysplastic with reduced mobility. Pulsed wave Doppler interrogation in the ascending aorta immediately distal to the aortic valve did not establish whether or not there was anterograde aortic blood flow. Colour flow imaging showed a turbulent blood flow pattern across the aortic valve (fig 1). The diameter of the functional aortic valve orifice was approximately $6 \mathrm{~mm}$ based on the width of the colour jet. The aortic arch was normal. Repeat fetal echocardiograms at 34 and 35 weeks' gestation showed progressive right ventricular dilatation with no change in left ventricular dimensions.

Because of the echocardiographic evidence of poor left ventricular function it was decided that delivery should be by elective caesarean section once pulmonary maturity could be established. Serial amniocenteses were performed twice weekly until 36 weeks, when the amniotic fluid biochemical profile was consistent with fetal pulmonary maturity. Subsequently a male infant weighing $3390 \mathrm{~g}$ was delivered by caesarean section. The infant was vigorous at birth; however, within minutes he showed evidence of poor peripheral perfusion with symmetrically weak pulses. Considerable bradycardia and cyanosis developed shortly afterwards and he was intubated and ventilated and started on continuous infusions of prostagladin $\mathrm{E} 1(0 \cdot 1 \mu \mathrm{g} / \mathrm{kg} /$ $\mathrm{min})$ and dopamine $(10 \mu \mathrm{g} / \mathrm{kg} / \mathrm{min})$.

Cross sectional echocardiography confirmed the 


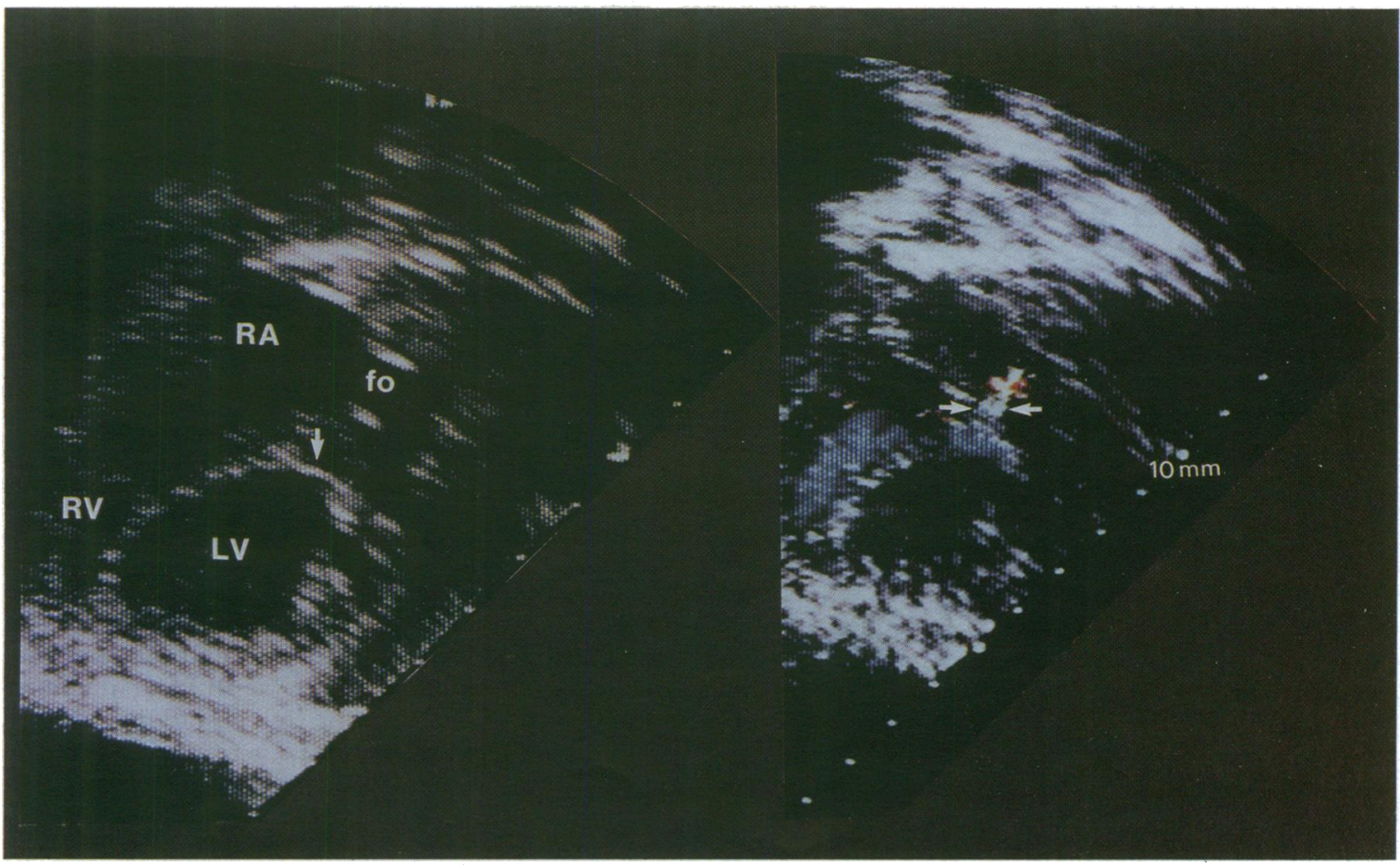

Figure (Left) Cardiac four chamber view showing a dilated left ventricle. The vertical arrow indicates a thickened immobile aort valve. (Right) Same view showing a pattern of turbulent blood flow across the aortic valve by colour Doppler. The effective diametê of the orifice is approximately $6 \mathrm{~mm}$. $R A$, right atrium; $R V$, right ventricle; $L V$, left ventricle; fo, foramen ovale.

diagnosis of aortic valve stenosis (annulus diameter $7 \mathrm{~mm}$ ). The pressure gradient across the left ventricular outflow tract calculated by Doppler echocardiography was only $10 \mathrm{~mm} \mathrm{Hg}$, which was consistent with the poor left ventricular function and low cardiac output. The ductus arteriosus was patent with right to left systolic shunting and no aortic coarctation. At approximately two hours of age the infant underwent a surgical aortic valvotomy under inflow occlusion. The procedure was well tolerated and positive pressure ventilation and inotropic support was stopped by the third postoperative day. On the second postoperative day the Doppler derived pressure gradient across the aortic valve had increased to $25 \mathrm{~mm} \mathrm{Hg}$. This value is consistent with improved left ventricular function. There was trivial aortic valve regurgitation.

The infant was discharged home on the tenth postoperative day. At follow up at six months the child was symptom free and thriving. Echocardiography showed normal left ventricular dimensions and a shortening fraction of $43 \%$. Doppler echocardiography showed a pressure gradient of $40 \mathrm{~mm} \mathrm{Hg}$ across the aortic valve.

\section{Discussion}

There are few published data on the fetal diagnosis and subsequent perinatal management of congenital cardiac lesions. A recent case report described an infant in whom aortic valve stenosis had been previously diagnosed in utero who was delivered by caesarean section at 35 weeks' gestation because there had been prolonged rupture of membranes, maternal fever, and leucocytosis. ${ }^{6}$ The prenatal diagnosis did not seem to influence the mode of delivery although the authors suggested that when there is left ventricular myocardial dysfunction delivery should be by caesarean section to avoid undue stress. We support this approach and suggest that when increasing myocardial dysfunction in utero has been shown the neonatal prognosis may be improved by early elective caesarean section once pulmonary maturity can be reasonably assured. These infants should be delivered in a tertiary care centre with expertise in neonatology, paediatric cardiology, and paediatric cardiac surgery. An elective caesarean section allows both the coordination of these specialists well in advance of delivery and the efficient postnatal man- 
agement and stabilisation of the infant. Once the condition of the infant is stabilised and the prenatal diagnosis is confirmed by echocardiography, aortic valvotomy, may be performed.

The concept that early delivery may be beneficial in certain cardiac lesions associated with fetal myocardial dysfunction is controversial. Although not proven, we speculate that in the case of critical aortic valve stenosis intrauterine myocardial dysfunction is progressive. Presumably high left ventricular pressures with increased wall stress are not adequately compensated by increased myocardial blood flow. This may result in myocardial ischaemia which is possibly more severe in the subendocardium. In addition, left ventricular end diastolic compliance would theoretically decrease thereby impairing left ventricular filling which in turn increases right ventricular volumes. In this case we saw progressive right ventricular dilatation in utero. Early delivery and relief of the left ventricular outflow tract obstruction may prevent further myocardial dysfunction and enhance postnatal recovery of cardiac function. In this infant there was rapid recovery of left ventricular function after surgical aortic valvotomy; but it is not known whether recovery would have been rapid had the pregnancy been allowed to progress to term.

For most cardiac lesions there is no significant deterioration in cardiac function in utero and therefore early delivery is not indicated. However, fetuses with cardiac lesions such as critical aortic valve stenosis with evidence of intrauterine myocar- dial dysfunction may benefit from early delivery and treatment. By adopting a coordinated, perinatal approach as outlined here we feel that the morbidity and mortality associated with neonatal critical aortic valve stenosis may be reduced. But a larger number of patients will have to be treated before any conclusions can be reached.

\section{References}

1 Duncan K, Sullivan I, Robinson P, Horvath P, deLaval $M$, Stark J. Transventricular aortic valvotomy for critical aortic stenosis in infants. $J$ Thorac Cardiovasc Surg 1987;93:546-50.

2 Dobell ARC, Bloss RS, Gibbons JE, Collins GF. Congenital valvular aortic stenosis: surgical management and long-term results. $J$ Thorac Cardiovasc Surg 1981;81:916-20.

3 Allan LD, Tynan M, Campbell S, Anderson RH. Identification of congenital cardiac malformations by echocardiography in midtrimester fetus. Br Heart $\mathrm{J}$ 1981;46:358-62.

4 Kleinman CS, Donnerstein RL. Ultrasound assessment of cardiac function in the intact human fetus. $\mathrm{J} \mathrm{Am}$ Coll Cardiol 1985;5:845-945.

5 St John Sutton MG, Gewitz MH, Shah B, et al. Quantitative assessment of growth and function of the cardiac chambers in the normal human fetus: a prospective longitudinal echocardiographic study. Circulation 1984;69:645-54.

6 Huhta JG, Carpenter RJ, Moise KJ, Deter RL, Ott DA, McNamara DG. Prenatal diagnosis and postnatal management of critical aortic stenosis. Circulation 1987;75:573-6. 